\title{
Research on Family Education in Remote Chinese Areas Impacted by COVID-19
}

\author{
Boce Feng \\ College of Economics and Management, Tianjin University of Science and Technology, Tianjin, China, 300211 \\ Corresponding author. Email:fengboce@163.com
}

\begin{abstract}
In China, family education in remote areas has always been an issue of great concern to the country and the education community. The outbreak of COVID-19 has brought education in remote areas into a special period. To better understand the current situation of family education in remote areas of China in the context of the epidemic, the author takes the Tacheng area of Xinjiang as an example and uses the method of questionnaire survey to analyze.This research takes 9-12-year-old adolescent students from a school in Tacheng area as the research object, takes the existing family education problems as the research direction, and carries out the investigation. The results show that there are some problems in this area, such as inter-generational education, insufficient parental education ability and poor parent-child relationship. The researchers believe that the region can improve and develop the problems from the aspects of promoting the relationship between family and school, improving parents' educational ability, perfecting and implementing local laws and regulations, and combing "learning awareness".
\end{abstract}

Keywords: COVID-19, family education, remote areas, education, parent-child relationship.

\section{INTRODUCTION}

At present, the outbreak of COVID-19 has brought China into a special period. During this period, the special scene shaped by the epidemic has brought different levels of influence on all aspects of country. As far as family education is concerned, the limitation of life scenes, Increasing external economic and other pressures and poor communication among family members have also prompted the emergence and changes of a series of family problems. On the other hand, due to the differences in local personnel composition, economic level and ideological consciousness, some inherent family education problems still exist and have changed under the special scene of COVID-19, so the emergence of this special scene has brought research value.

Under the current situation, some scholars have conducted research on family education, among which representative ones are: $\mathrm{Qu}$ Xiaoling believes that the family education problems exposed by COVID-19 include three problems: lack of life education, good living habits having not been developed, and insufficient penetration of family and country consciousness [1]. Guo Yuying and Wei Ge said in the study of parent-child relationship during the new crown pneumonia epidemic: during the home isolation period, the crisis of parent-child relationship is mainly caused by the shrinking living area, increasing social pressure, and poor intergenerational communication [2]. Xinjiang borders on eight countries and is located in the front line of epidemic prevention and control in China. There is a situation of multi-ethnic settlement and cultural blending of Han and Uygur. Tacheng region in Xinjiang, as an important city and a major center in the northwest of the autonomous region, is concentrated in local schools, and its particularity can be better reflected in epidemic prevention and control, cultural integration and other aspects. The existence of particularity can help the author analyze forms and find problems; On the other hand, Tacheng area in Xinjiang is located in the frontier, far from the center of our country, which is in line with the setting of remote areas in the study, so the researchers choose Tacheng area schools in Xinjiang as the research object. The author designs research questions from three directions: basic family information, parents' educational ability, and family parent-child relationship. The main research method is to issue questionnaires to local school students, and to use interviews with local students as a supplement. On the one hand, the study expands the related research on COVID-19, and fills part of the blanks. On the other 
hand, it is intended to arouse public concern about the special education of family education in remote areas. It also provides a reference for the research and development of family education in Tacheng, Xinjiang.

\section{THE CONCEPT OF FAMILY EDUCATION AND RESEARCH ON FAMILY EDUCATION IN REMOTE AREAS OF CHINA}

\subsection{Concept}

Family education is independent of school education. Due to differences in economic levels and many aspects, the situation of students' family education varies. For the definition of the term family education, Zhao Zhongxin pointed out in the book "Family Education": Family education in a narrow sense refers to the implementation of family education by parents.

Family education in a broad sense should be an education implemented by family members. ...In the family, whether it is parents to children, children to parents, elders to young people, or young people to elders, all purposeful and conscious influences are family education [3]. "Family Education" edited by Zuojun Deng pointed out: family education takes place in family life. Educational activities centered on parent-child relationship and aimed at cultivating people in need of society are in the process of human socialization [4]. Some scholars believe that: in the broadest sense of the term, family education is an inclusive term referring to all educational practices, offered by mental health professionals and others [5].

\subsection{Related research}

Regarding the current situation of family education in China, Zou Qiang believes that: compared with traditional family education tasks that are mainly limited to ethical education, contemporary parents' understanding of the tasks undertaken by family education has many new changes. Firstly, Family education should undertake the purpose of promoting the all-round development of children. Many parents attach great importance to the education of their children in various aspects. Secondly, Pay attention to the role of family education in promoting children's socialization and focus on the combination of life education and talent education [6].

Focusing on family education in remote areas, Huang Zibo found four problems in his research on family education in remote rural areas. Firstly, family education in remote rural areas is restricted by local economic conditions. Secondly, parents' education level affects families education; Thirdly, there is a deviation in the understanding of the relationship between family education and school education. Lastly, the family education management mechanism is not perfect [7] After the emergence of COVID-19, some new changes in living conditions further gave birth to new changes in family education in remote areas, so this article aims to analyze the current situation in the context of the epidemic.

\section{RESEARCH METHODS}

The research mainly adopts the way of questionnaire survey in a school in Tacheng area, Xinjiang. The area is located in a remote area on the China-Kazakhstan border. The local staff structure is a mixture of Han and ethnic minorities. The school is the only school in the area. It recruits students from the first grade to the third grade of junior high school. The total number is about 180 to 200 . This study selects a group of teenagers aged 9-12 years old to understand the current situation and problems in an anonymous manner. A total of 12 questions is designed in the questionnaire, and three aspects are covered in the question design of the questionnaire:

Firstly, the survey of basic family information. The survey mainly involves the age of the educated, the size of family members and the main implementers of family education. In order to have a preliminary understanding of the family environment of the students in the region under the background of the epidemic, and provide an environmental basis and comparative variables for the follow-up problem research. At the beginning of the problem design, the researcher paid attention to the family size and the issue of changes in education implementers.

Secondly, the investigation of parents' educational ability. The educational level of parents, the choice of focus in the education process, and the attitudes, methods towards the educated can more intuitively reflect the differences in the educational abilities of the parents and the problems existing in family education.

Thirdly, the investigation of the parent-child relationship of the family. During the home isolation period of the epidemic, a special scene of family education was created. This special scene undoubtedly increased the mutual communication and mutual influence between parents and students. Parent-child relationship is an important form of expression in this environment, so the survey of the relationship between parent and child can well reflect the development of family education.

Among the three research directions, the design of the question pays special attention to the existing family education problems such as inter-generational education, over-focused education, and parent-child relationship affecting education. 


\section{ANALYSIS OF RESEARCH RESULTS}

In this study, more than 60 questionnaires were distributed to the target group. After collecting questionnaires, screening and deleting invalid questionnaires, and merging the same information, a total of 46 valid questionnaires were obtained. Under the premise of content validity analysis, through the analysis of the questionnaire survey results, it was found that the family education in this area has the following characteristics:

\subsection{Family education members are fixed and inter-generational education exists}

The family structure of the students in this school is mainly two kinds of family structures. Namely: "family of three": child, father, mother; "family of seven": child, parents, grandparents, and grandparents.

As shown in Figure 1, "Which family member do you have the most contact with in your daily study and life?" In the answer to the question, it can be found that in daily life, students whose parents implement family education account for nearly the majority. However, about $18 \%$ of the students are still taught by grandparents or grandparents. The questionnaire survey involved the investigation of the basic family status in the two phases before and after the epidemic. It was found that, except for a few exceptions, there was no significant difference in factors such as the number of households and family members contacted by local students before and after the epidemic. The living mode of the local family is relatively stable and less affected by the outside world.

As far as education implementers are concerned, the traditional problem of inter-generational education still exists. For the grandparent's generation, For grandparents' parents, facing the problem of educating the next generation, they are faced with a series of difficulties and challenges, such as whether their way of thinking can keep pace with the times, whether their own ability can be competent, whether they are full of physical strength and energy and so on.

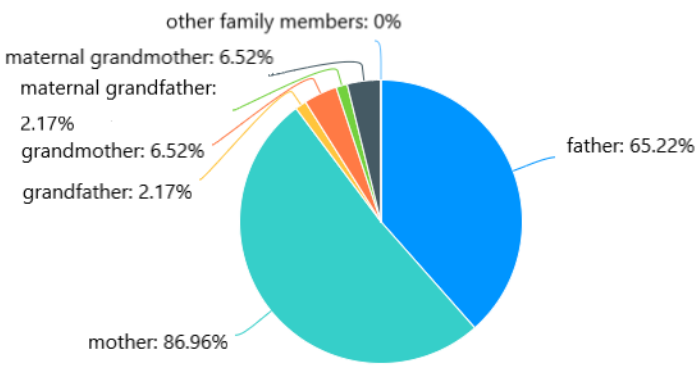

Figure 1 : The proportion of parents having the most contact with students
(Note: Figure 1 Percentage $=$ The number of times this option has been selected/Number of valid answer sheets)

\subsection{The implementer's educational ability is insufficient}

In the process of family education, the educational ability of parents directly affects the results of family education. With the development of education and the improvement of parents' education level, the level of parent education is also improving. However, there are still quite a few parents who have lagging educational concepts and neglect their own learning. They love their children too much, but they do not love them too much [8]. In the process of surveying parents in this questionnaire statistics, it is found that educational problems caused by parents' lack of educational ability still exist.

\subsubsection{Parents' educational level does not match the family's educational needs}

In this statistical questionnaire(as shown in figure 2), more than half of the parents with a degree below high school, and mostly concentrated in elementary school and junior high school. Parents with a college degree or above account for only less than $50 \%$, which obviously cannot fully satisfy the current family educational needs.

The low educational background of parents is most intuitively reflected in solving students' difficulties in school and after-school tasks, "In the daily study life, do parents help you with school homework and other tasks?" "Do you think they are you competent?" In the answer to this question, the survey results (as shown in figure 3 ) showed that $36.96 \%$ of parents ignored school homework and other tasks, and only a small percentage of the total number of parents were able to solve most of the problems. $2.17 \%$. It can be seen that the general low academic qualifications and the connection with school education can well reflect the problems of family education.

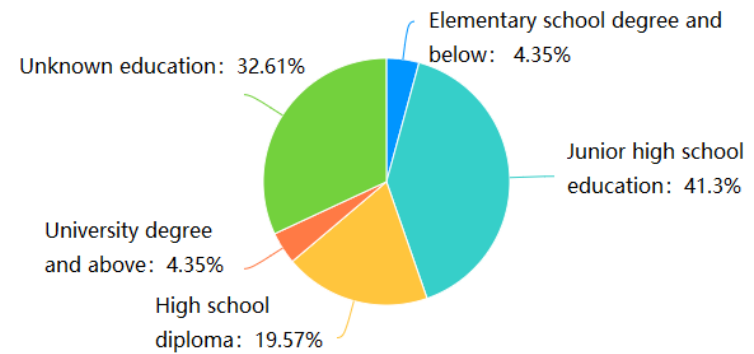

Figure 2 : The percentage of parents' educational level 


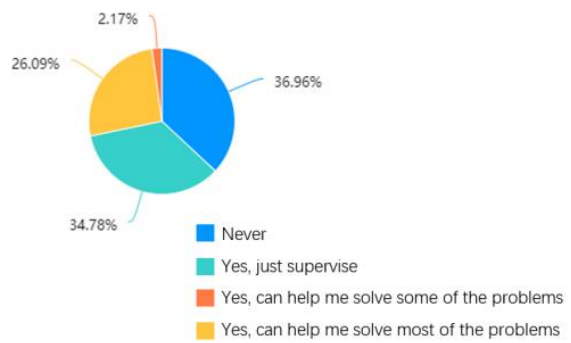

Figure 3 : Proportion chart of whether parents can help complete school tasks

\subsubsection{Parents pay too much attention to} "intellectual education" and the phenomenon of comparison exists

Family education is too single-minded and pays too much attention to "intellectual education", that is, academic achievement and mutual comparison, which has been an old problem in the development of family education for many years. As early as 2019, Shuang Luo and Dong Wang said in a survey on the current situation of family construction in 13 provinces of China: Parents still place intellectual education in the most important position of family education, causing anxiety about their children's education [9].

This problem also exists in this region. In the survey samples, the over-professionalism of education is reflected in the excessive emphasis on intellectual education and the excessive attention of some parents to performance. "In your daily life, which aspect of your parents care about you most?" In the answer to this question, as shown in figure 4 , in addition to basic physical health, most parents put the focus of education on academic performance, and pay less attention to the improvement of personal emotions, hobbies and physical fitness. In terms of academic performance, nearly $50 \%$ of parents are concerned about the difficulties and attitudes in the learning process, while another part of parents only care about academic performance and do not pay attention to the process of education. In the following-up survey, health and performance are excluded, $52.17 \%$ of the parents choose not to pay attention to other content, which also leads to the lack of comprehensive and in-depth family education. There is a phenomenon in which parents use their children to compare with each other in family education. For the answer to the question "Do you think your parents compare you with other classmates?", the survey showed that only about $17 \%$ of students said their parents never compared them with others. This shows the anxiety of parents and the improper way of education.

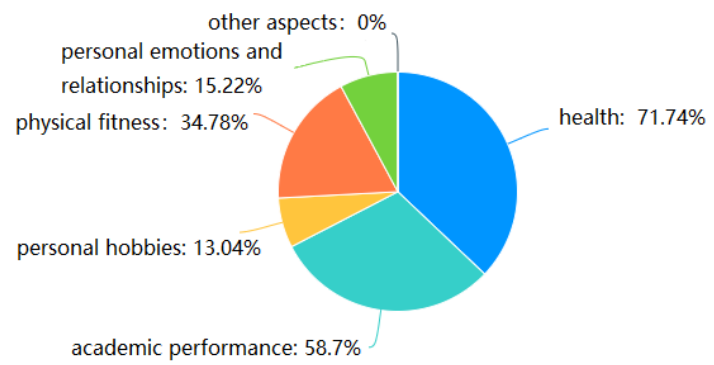

Figure 4: The proportion of the most concerned aspects of parents in daily life

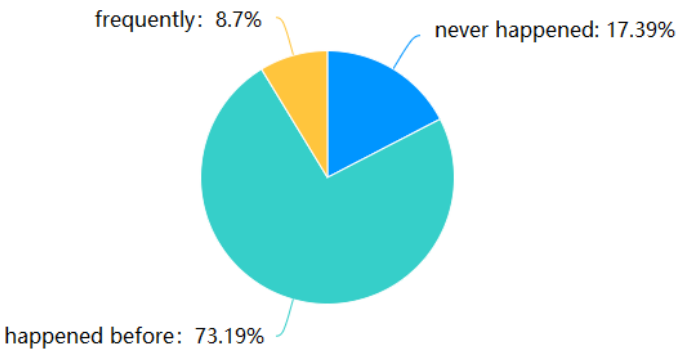

Figure 5: Whether parents compare with each other in terms of children's academic performance

\subsection{The problem of parent-child relationship mode still exists}

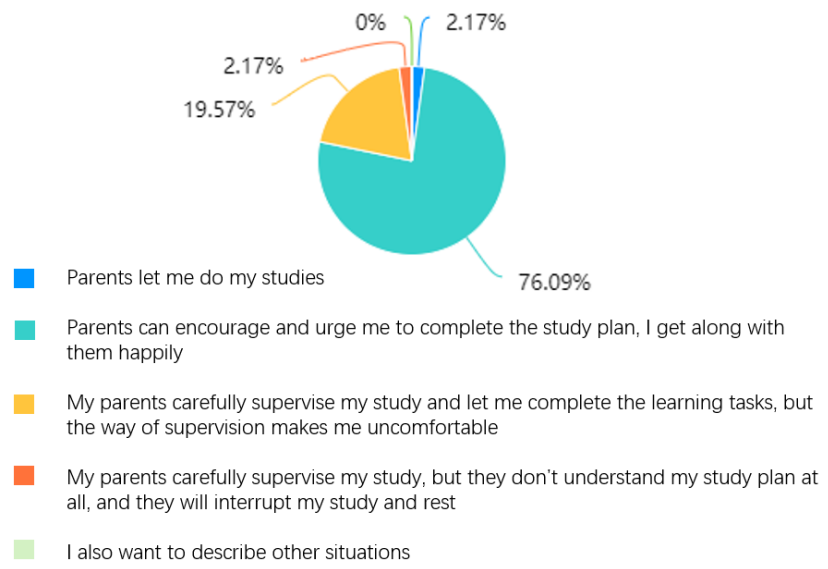

Figure 6: The proportion of parents and students getting along with each other in learning during the epidemic 
The special scene of the epidemic also affects the parent-child relationship mode and parent-child relationship. In the answer to the question "during home study, parents have different attitudes and roles towards your learning plan (including the school plan and their own learning plan), which situation do you think is most similar to you?", as shown in figure 6 , although most students think that they get along well with their parents.However, regardless of whether the students hide the existence of the problem, this questionnaire survey found that nearly $20 \%$ of the students still feel that their parents' way is inappropriate during the epidemic isolation period.

In other parts of China, after interviews with family education, researchers found that the issue of parent-child relationship during the epidemic is still a difficult problem. "If you don't do your homework, you will be kind to the father and your son. When you do your homework, you will jump like a dog". Once it became a hot topic in society. In a researcher's interview with a student, the student mentioned the parents' incomprehension and dis-support of their own learning plan. The student said that his parents always urge him to study too much during his rest practice, which caused him not to relax. He did not control the volume of playing on the phone while he was studying. In his opinion, the influence of his parents on his learning is not positive, but disrupts his learning rhythm and affects his learning efficiency.

\section{SOLUTION MEASURES}

Based on the above analysis of the data, the article reflects the existence of a series of problems caused by intergenerational education in the Tacheng area, problems caused by the lack of parental education, and three major problems affecting parent-child relationships due to the epidemic. Based on the existing problems, the researchers believe that improvements should be made from the following three aspects:

\subsection{Enhance of "home-school interaction"}

Compared with school education, family education is more affected by parents. Local schools can organize a more professional team of teachers to enhance and improve local family education based on the actual situation, such as the after-school tutoring work being carried out in the local area. As a medium and carrier, the school uses activities as a platform and an opportunity to pass the correct form of family education from the classroom to the family, further enhance the parent-child relationship, and let more professional teachers and rich school activities serve as levers to leverage family education activities to build a learning family.

\subsection{Using external forces to promote the improvement of parents' educational ability}

Parents are an indispensable and important part of family education. Local education departments can organize public welfare training for parents in conjunction with schools, so as to regularly publicize correct family education awareness to parents. Establishing a correct educational concept from the parents' side to promote the discovery and correction of family education problems. Or setting up a special community counseling department with the community as the unit.

\subsection{Popularizing laws and regulations}

In accordance with the promulgation and implementation of the "Family Education Promotion Law of the People's Republic of China", local governments can issue relevant regulations and guide and publicize them. Let parents understand their responsibility for family education, and ensure that local young people and children receive good family education and enjoy the bottom line of a good family environment.

\section{THOUGHTS ON THE WHOLE COUNTRY}

\subsection{Thinking about the whole country caused by the situation in Tacheng, Xinjiang}

The reason why the author pays attention to the problem of family education in Tacheng area of Xinjiang is that the region is located in a remote area in the west, and its economic level is relatively backward compared with eastern cities in my country, and it is on the front line of epidemic prevention. Local policies and life are greatly affected by the epidemic. Looking at the whole country, on the one hand, areas with the same characteristics still exist in our country.

In the remote areas of southwest, there is also a problem that parents are not well-educated and difficult to carry out family education. And with the development of the current information age, the difference between remote areas and better economic conditions is also deeply rooted in the local people. This has caused parents in some areas to pay more attention to the improvement of academic performance and ignore other aspects of family education. The problem is similar to the problem of over-focusing on intellectual education in the Tacheng area.

In addition, it will also be affected by other conditions such as traffic inconvenience.In other areas of our country, such as our country's major cities, the "Tacheng Family Education" problem also exists to varying degrees. During the epidemic isolation period, 
the issue of parent-child relationship has become a common concern of the people. It can be seen that, the existing problems of family education are still worthy of in-depth exploration and thinking.

\subsection{Other feasible suggestions}

Because of the prevalence of the problem, the national and local governments at all levels are also paying close attention. The author believes that in addition to the improvement and implementation of laws and regulations, governments at all levels have another point worthy of key investment, that is, starting with awareness propaganda and establishing learning awareness. In the past two years, "learning" related vocabulary has emerged endlessly, ranging from "learning society", "learning community" to "learning family", which illustrates the importance of learning awareness.

The construction of "learning awareness" can be understood from two aspects. On the one hand, it is the consciousness of active learning. Based on the existing material conditions, learning can be integrated into daily life. Both parents and students can learn actively and love learning; on the other hand, it is the consciousness of mutual learning. Establishing opportunities and bonds for mutual learning with people, collectives and collectives, and establishing mutual learning and mutual help equality relationships in all aspects of learning and family education are conducive to the construction of learning concepts. The establishment of the "learning concept" can give play to subjective initiative to make up for the lack of objective factors to achieve the improvement of the problem.

\section{CONCLUSION}

After the investigation of students in Tacheng School in Xinjiang and the analysis of the research results, the study found that the area has problems such as inter-generational education, insufficient parental education capabilities, and poor parent-child relationships. The researcher believes that the region can improve and develop the problems in terms of promoting the connection between the family and the school, externally improving the educational ability of parents, the improvement and implementation of local laws and regulations, and the establishment of a "learning awareness". It can be seen from Xinjiang that the problem of family education in remote areas of China under the background of epidemic situation deserves attention and consideration.

The survey has certain limitations. The survey data are timely. Changes in the form of epidemic prevention and control and local form will lead to the research results may be different from the actual local results. In future research, the author will focus on remote areas under the background of the new crown epidemic, and will further expand the scope of data collection to find commonalities, and find and solve problems that exist.

\section{REFERENCES}

[1] Qu Xiaoling. Reflection on family education in the context of the new crown pneumonia epidemic [A]. Sichuan Science and Education Maker Research Association, Sichuan Science Fiction World Magazine Co., Ltd. Proceedings of 2020 Science and Education Innovation Symposium (Fourth Series) [C ]. Sichuan Science and Education Maker Research Association, Sichuan Science Fiction World Magazine Co., Ltd.: Sichuan Science and Education Maker Research Association, 2020: pp. $1-4$.

[2] Guo Yuying, Wei Ge, Yan Min. The crisis and reshaping of the parent-child relationship during the new crown pneumonia epidemic: the perspective of family emotional practice[J]. Adolescent and Child Research, p.1.

[3] Zhao Zhongxin: "Family Education", People's Education Press, 1994 edition, p.5.

[4] Deng Zuojun, editor: "Family Education", Fujian Education Press, 1995 edition, p. 7

[5] van Schalkwyk G.J. (2018) Family Education. In: Kreutzer J.S., DeLuca J., Caplan B. (eds) Encyclopedia of Clinical Neuropsychology. Springer, Cham. https://doi.org/10.1007/978-3-319-57111-9_9163 p. 1 .

[6] Zou Qiang. Research on the changes of contemporary family education in China[D]. Central China Normal University, 2008, p. 129.

[7] Huang Zibo. Research on the status quo and improvement strategies of student family education in remote rural areas - Based on $\mathrm{X}$ area as an example [J]. Shanxi Youth, 2021(08): 65-66.

[8] The Ministry of Education Cares for the Next Generation Working Committee "The Characteristics, Ideas and Methods of Family Education in the New Era" Research Group. The status quo, problems and policy recommendations of family education in my country [J]. People's Education, 2012(01): 6 -11.

[9] Luo Shuang, Wang Dong. Investigation on the status quo of family construction in my country and policy enlightenment - Based on a questionnaire analysis of 13 provinces, autonomous regions and municipalities across the country $[\mathrm{J}]$. Chinese Family Education, 2021(03): 32-40. 